\title{
New biologics in the management of Crohn's disease: focus on certolizumab pegol
}

REVIEW

This article was published in the following Dove Press journal:

Clinical and Experimental Gastroenterology

18 June 2009

Number of times this article has been viewed

\author{
Elisabetta Colombo' \\ Fabrizio Bossa' \\ Anna Latiano ${ }^{2}$ \\ Orazio Palmieri \\ Angelo Andriulli, ${ }^{1,2}$ \\ Vito Annese ${ }^{2,3}$ \\ 'Unit of Gastroenterology, \\ ${ }^{2}$ Laboratory of Genetic Research, \\ ${ }^{3}$ Unit of Endoscopy, Department \\ of Medical Sciences, IRCCS-CSS \\ Hospital, San Giovanni Rotondo, Italy
}

\begin{abstract}
Crohn's disease (CD) is a chronic inflammatory condition involving the gastrointestinal tract characterized by recurrent exacerbations and remission. The disease frequently occurs in the lower part of the small bowel, but can affect any part of the digestive tract, from the mouth to the anus. The traditional goals of treatment of Crohn's disease were to induce and maintain clinical remission. More recently targets such as mucosal healing, reduced hospitalization and surgery, and improved quality of life are becoming increasingly achievable. The general principles for treatment should consider clinical activity, site and behavior of disease; however, the appropriate choice of medication depends on many factors that are the best tailored to the individual patient. This review focuses on certolizumab pegol, the first Fc-free PEGylated Fab' fragment of humanized monoclonal antibody that binds and neutralizes human tumor necrosis factor alpha. Data on indication, pharmacokinetics, efficacy, safety, and influence on quality of life are reviewed.
\end{abstract}

Keywords: Crohn's disease, certolizumab (CDP870), antiTNF- $\alpha$ agents

\section{Introduction}

Crohn's disease is a chronic inflammatory condition involving the gastrointestinal tract characterized by recurrent exacerbations and remission. The disease frequently occurs in the lower part of the small bowel, but can affect any part of the digestive tract, from the mouth to the anus. The most common symptoms are abdominal pain, often in the lower right region of the abdomen, diarrhea, often with blood and/or mucus in the stool, weight loss, anorexia, fever, and extra-intestinal manifestations (ie, localized to the eyes, skin, and joints). ${ }^{1 \cdot}$ In addition, approximately $10 \%$ of Crohn's disease patients have perianal fistulas at the diagnosis. ${ }^{2}$

The goal of treatment should be to induce clinical remission, while bearing in mind the most appropriate means of maintaining remission. This actually may require a "step up" regimen, where less potent/toxic approaches are used as first-line therapy, although in selected patients, a "top down" approach using as first-line biological therapy could be appropriate.

\section{Epidemiology, genetic background and pathogenesis}

A consistent geographical variation in incidence rates has been reported varying from 3.6 to 15.6 cases per 100,000 person-years in North America, 0.7 to 9.8 cases per 100,000 in Europe, and 0.5 to 4.2 cases per 100,000 in Asia. ${ }^{3}$

The wide regional and racial variation suggests an important genetic component in the pathophysiology of the disease or a distinct environmental contribution. 
The disease tends to occur slightly more frequently in women $(50 \%$ to $60 \%)$ than in men, ${ }^{4}$ and while most patients are diagnosed in their twenties and thirties, about $10 \%$ to $15 \%$ are diagnosed in childhood. ${ }^{5}$

Crohn's disease is widely believed to originate from a dysregulated immune response to luminal bacteria, in a genetically susceptible host. ${ }^{6}$ The inheritance model is non-Mendelian but complex-polygenic, with several genes involved together and interacting with environmental factors.

Concordance data in monozygotic twins (36\% to $58 \%$ ) and the high relative risk for first-degree relative (up to 20 to 35) have provided strong epidemiological evidence for a genetic contribution. ${ }^{7}$ These observations led to development of genetic investigations with two broad strategies: one has investigated candidate genes whereas the other used hypothesis-free methods like genome-wide scanning.

The NOD2 gene (nucleotide-binding oligomerization domain 2) on chromosome 16q12 was the first susceptibility gene for Crohn's disease to be successfully identified in 2001 among Caucasians. ${ }^{8}$ NOD2 gene encodes an intracellular receptor predominantly expressed in monocytes and Paneth cells. ${ }^{9}$ The coded protein is activated by muramyldipeptide (MDP), a component of peptidoglycan in bacterial cell walls and subsequently will activate the nuclear factor- $\kappa \mathrm{B}$ signaling pathway, and stimulate secretion of antimicrobial peptides including defensins. ${ }^{10}$ NOD2 variants are more prevalent in patients with ileal Crohn's disease and seems to predispose for a stricturing phenotype and need for surgery. ${ }^{11-16}$

More recently, a number of genome-wide association studies $^{17}$ and a meta-analysis ${ }^{18}$ have identified more than 30 Crohn's disease susceptibility loci.

The contribution of environmental factors is more puzzling. Given that the incidence of disease appears to increase as countries become more developed, it is likely that some components of disease are triggered by an industrial environmental (diet or changes in exposure to pathogens); moreover, higher incidence of disease is associated with higher socioeconomic status. ${ }^{9}$ Of the environmental factors thought to affect disease susceptibility, only smoking and appendectomy have a substantive evidence base. . $^{3,20}$

In conclusion, the current hypothesis on pathogenesis suggests that Crohn's disease is the result of an exaggerated immune response against intestinal microflora by activation of $\mathrm{T}$ cells and overexpression of inflammatory cytokines in a genetically predisposed host. ${ }^{18}$ The classic immunological paradigm focuses especially on type 1 helper T-cell (Th1) cytokines, especially tumor necrosis factor alpha (TNF- $\alpha$ ), although more recently the Th17 pathway is receiving increasing attention. $^{21,22}$

\section{Principles of medical therapy}

The main goal of the treatment of Crohn's disease is to induce clinical remission. The appropriate choice of medication depends on many factors that are the best tailored to individual patient. The choice is often influenced by the balance between drug potency and site effects, previous response to treatment, or presence of extra-intestinal manifestation.

New therapeutic approaches over the last decade have focused on the immunological mechanisms associated with the pathogenesis of Crohn's disease, especially the blocking of TNF- $\alpha$.

TNF is a proinflammatory cytokine which is a key mediator of inflammation. It can be detected at high concentrations in diseased areas of the bowel wall and in blood and feces of patients. ${ }^{26-28}$ AntiTNF- $\alpha$ acts by binding to both soluble and trans-membrane forms of TNF- $\alpha$, inhibiting its immediate pro-inflammatory actions, and the production of other proinflammatory mediators. In vitro studies have demonstrated that antiTNF- $\alpha$ agents reduce the production of chemokines and upregulation of endothelial adhesion molecules; this in turn decreases the migration of inflammatory cells, reduces granulocyte-macrophage colony-stimulating factor (GM-CSF) production in intestinal mucosal T cells, and may in turn induce $\mathrm{T}$ cells apoptosis.

Infliximab was the first antiTNF- $\alpha$ antibody approved by FDA for treatment of Crohn's disease. However, its chimeric composition has been associated with problems of immunogenicity, which may lead to infusion reactions and loss of efficacy. ${ }^{29}$ More recently several other biologics have been investigated for treatment of Crohn's disease: adalimunab, natalizumab, CDP871, and certolizumab. The last named has been approved by FDA for adults with moderate to severe Crohn's disease not responding to conventional therapy. ${ }^{30}$

Our aim is to provide a comprehensive, up-to-date review of indication, pharmacokinetics, efficacy, safety, and influence on quality of life of certolizumab.

\section{Mechanism of action of certolizumab pegol (CDP870)}

Certolizumab pegol is the first Fc-free PEGylated Fab' fragment of humanized monoclonal antibody that binds and neutralizes human TNF- $\alpha$. The pharmacokinetic properties of the Fab' fragment in vivo are usually poor. However, attachment of the $40 \mathrm{kDa}$ polyethylene glycol (PEG) moiety markedly increases the half-life of certolizumab to a value 
comparable with that of the whole-antibody product. The Fab' fragment was engineered with a single free-cysteine residue in the hinge region, which enables site-specific attachment of PEG without affecting the ability of the Fab' fragment to bind and neutralize TNF- $\alpha$. The structure of certolizumab pegol differs from that of other antiTNF- $\alpha$ agents that have been tested for treatment of Crohn's disease. Infliximab, adalimumab, and etanercept are all based on the human IgG1 Fc, are capable of fixing complement and binding to Fc receptors, and therefore have the potential for Fc-mediated effect.

The mechanisms of action believed to be essential for the efficacy of antiTNF- $\alpha$ agents in Crohn's disease are:

Induction of apoptosis of both monocytes and T cells, ${ }^{31-34}$ Neutralization of soluble and membrane-bound TNF- $\alpha \cdot ;^{33}$

Antibody-dependent cell-mediated cytotoxity (ADCC) and complement-dependent cytotoxity (CDC); ${ }^{35}$

Reverse signaling via mTNF- $\alpha .^{36}$

In vitro studies have demonstrated that infliximab, certolizumab, adalimumab, and etanercept are all able to neutralize soluble TNF- $\alpha$ and membrane-bound TNF- $\alpha$. Infliximab and adalimumab are comparable in their ability to mediate complement-dependent cytotoxicity, and antibody-dependent cell-mediated cytotoxicity. Moreover, they equally increase the proportion of cells undergoing apoptosis and the level of granulocyte degranulation. Etanercep mediated these effects to a lesser degree, while certolizumab pegol did not exhibit increased levels of apoptosis, suggesting that these mechanisms are not essential for the efficacy of antiTNF- $\alpha$ agents in Crohn's disease. ${ }^{32}$ This probably happens because certolizumab pegol does not contain Fc region, which is normally present in a complete antibody, and therefore does not fix complement or cause antibody-dependent cell-mediated cytotoxicity. ${ }^{38}$

Despite the fact that certolizumab pegol is a monovalent antibody fragment, its in vitro potency is greater than that of bivalent antibody adalinumab and infliximab. ${ }^{39}$

The site-specific addition of two molecules of PEG to the antibody fragment increases the plasma half-life to approximately 2 weeks, thus reducing the frequency of dosing.

\section{Efficacy study of certolizumab pegol (CDP870)}

At the moment three clinical trials have evaluated the short-term efficacy of certolizumab for induction of clinical response and remission in patients with active Crohn's disease..$^{40}$

In these studies the clinical response was defined as a decrease of $\geq 100$ points from baseline Crohn's Disease
Activity Index (CDAI) and remission was defined as a CDAI score of $\leq 150$ points.

The phase II trial by Winter $^{41}$ was a randomized, multicenter, placebo-controlled study, which aimed to evaluate the efficacy and safety of a single intravenous (iv) administration of different doses of certolizumab in adult patients with moderate to severe Crohn's disease. At the screening, patients were randomized into four treatment groups: certolizumab $1.25 \mathrm{mg} / \mathrm{kg}, 5 \mathrm{mg} / \mathrm{kg}, 20 \mathrm{mg} / \mathrm{kg}$, or placebo. The $5 \mathrm{mg} / \mathrm{kg}$ dose of certolizumab was equivalent to a $400 \mathrm{mg}$ subcutaneous dose of certolizumab. Ninety-two adult patients were enrolled into the study and were permitted to receive concomitant medication (azathioprine, methotrexate, antibiotics, mesalazine, corticosteroids) provided that dose had been stable prior to the start of the study. No significant differences in baseline demographics between treatment groups were found.

At week 4 (primary endpoint) there were no statistically significant differences in clinical response for any of the certolizumab groups compared with placebo (Table 1). A post-hoc analysis at week 2 indicated that the certolizumab $10 \mathrm{mg} / \mathrm{kg}$ dose had induced remission in a statistically significant number of patients compared with placebo: $47.0 \%(95 \%$ CI $0.4-73.7)$ vs $16 \%(95 \%$ CI $0.0-32.4)(\mathrm{p}=0.041)$. Moreover, at week $447.1 \%$ of patients treated with certolizumab $10 \mathrm{mg} / \mathrm{kg}$ were in remission compared with $20 \%$ of placebo group. However, these rates of response were not sustained at week 12 when only $23.5 \%$ of patients in certolizumab $10 \mathrm{mg} / \mathrm{kg}$ were in remission compared with $32 \%$ of patients in the placebo group.

The lack of difference of clinical response between the certolizumab-treated groups and placebo was probably due to the high response rate observed in the placebo group (52\% to 60\%). This finding was in contrast to the relatively low placebo response rate observed in a similar study with infliximab (12\% to $17 \%$ ). Patient response rate may be influenced by a variety of factors, such as use of corticosteroids, surgery and concomitant therapy. In addition, high placebo response rates may also be an artifact of the calculation of CDAI score, because of the high degree of subjectivity of this index as an indicator of disease activity.

Table I Clinical response to certolizumab pegol (CDP870) vs placeb at week $4^{41}$

\begin{tabular}{lllll}
\hline CDAl & \multicolumn{2}{l}{ CDP870 dose } & Placebo \\
\cline { 2 - 4 } & $\mathbf{5} \mathbf{~} \mathbf{g} / \mathbf{k g}$ & $\mathbf{1 0} \mathbf{~} \mathbf{~ g} \mathbf{k g}$ & $\mathbf{2 0} \mathbf{~} \mathbf{g} / \mathbf{k g}$ & \\
\hline Response $(\%)$ & 60.0 & 58.8 & 47.8 & $56.0 \%$ \\
$(95 \% \mathrm{Cl})$ & $(38.8-81.2)$ & $(32.5-85.2)$ & $(25.2-70.4)$ & $(34.5-77.5)$ \\
\hline
\end{tabular}


The phase II, multicenter, randomized, double-blind placebo-controlled, dose-response trial by Schreiber et al was designed to assess the efficacy and safety of subcutaneous certolizumab $100 \mathrm{mg}, 200 \mathrm{mg}, 400 \mathrm{mg}$, or placebo administered at week 0,4 , and $8 .{ }^{42}$ Efficacy assessments were performed every 2 week up to week 12, with a further 8-week follow-up evaluation for safety. A total of 291 patients were included in the study. Concomitant therapy with steroids, mesalamine or immunosuppressants was permitted if the patient was on a stable dose that could be continued throughout the 12-week duration of the double-blind phase. Patient characteristics were generally well balanced among treatment groups, although the mean age of patients receiving certolizumab was higher than in the placebo group. The greatest difference among the groups was a small preponderance of women in the placebo group. The use of concomitant medications were broadly similar among groups; the greater difference was observed for overall glucocorticoid use: $39.7 \%$ in the placebo group and $30.6 \%$ in the certolizumab $400 \mathrm{mg}$ group.

For the primary endpoint, all doses of certolizumab produced at week 2 a statistical benefit compared with placebo (Table 2). Certolizumab also showed significantly higher efficacy compared with placebo at week 4, 8, and 10 (only for $400 \mathrm{mg}$ dose). Patients receiving the $400 \mathrm{mg}$ dose showed the highest response rate at all time points, with the highest response observed at week $10(52.8 \%$ vs $30.1 \%$ in placebo group). However, at week 12 the difference between the certolizumab- and placebo-treated groups did not reach statistical significance. There was no effect of gender or concomitant therapy on the clinical response rate. The same was observed for the remission rate at weeks 4 and 12. A post-hoc analysis according to baseline C-reactive protein (CRP) concentration was performed since CRP serum concentration usually provides an objective criterion of inflammatory activity. ${ }^{43}$ Increased serum concentrations of CRP have been reported as a regular feature of patients with active disease. In asymptomatic patients, increased levels of this protein may indicate subsequent clinical relapse. Indeed, in patients with baseline CRP levels of $10 \mathrm{mg} / \mathrm{L}$ or greater, treatment with certolizumab $400 \mathrm{mg}$ resulted in a statistically significant benefit at all time

Table 2 Global benefit at week 2 post-injection of certolizumab pegol (CDP870) vs placebo ${ }^{42}$

\begin{tabular}{ll}
\hline Placebo & $\mathbf{I 5 . 1 \% ( 9 5 \% ~ C l , ~ 6 . 2 - 2 4 . 0 )}$ \\
\hline CDP870 100 mg & $29.7 \%(95 \% \mathrm{Cl}, \mathbf{1 8 . 6}-40.8)(\mathrm{p}=0.033)$ \\
CDP870 $200 \mathrm{mg}$ & $30.6 \%(95 \% \mathrm{Cl}, 19.2-41.9)(\mathrm{p}=0.026)$ \\
CDP870 $400 \mathrm{mg}$ & $33.3 \%(95 \% \mathrm{Cl}, 21.8-44.9)(\mathrm{p}=0.010)$ \\
\hline
\end{tabular}

points throughout the 12-week study in terms of both rates of clinical response and remission. In patients with baseline CRP less than $10 \mathrm{mg} / \mathrm{L}$, none of active treatments achieved a statistical difference from placebo, both of clinical response and remission rates. In patients with baseline CRP concentration $\geq 7$ to $10 \mathrm{mg} / \mathrm{L}$ who received certolizumab $400 \mathrm{mg}$, the clinical response rates at week 12 showed statistically significant difference from placebo. Accordingly, placebo response rates decreased with increasing baseline CRP level.

The phase III randomized, double-blind, placebo-controlled trial by Sandborn et al PRECISE 1 (Pegylated antibody fRagment Evaluation in Crohn's dIsease: safety and Efficacy 1$)^{44}$ was designed to evaluate the efficacy and safety of certolizumab $400 \mathrm{mg}$ or placebo subcutaneously at week 0, 2, 4 and then every 4 weeks. Patients were followed through week 26. Randomization was performed centrally and was stratified according to the serum level of CRP ( $\geq 10 \mathrm{mg} / \mathrm{L}<10 \mathrm{mg} / \mathrm{L}$ ) and concomitant therapy. Patients could receive concomitant therapy with stable doses of mesalamine, steroids, and immunosuppressive drugs. The baseline characteristics were similar in the two groups of patients. The study was conduct on 662 adults with moderate-to severe Crohn's disease. Among patients with a baseline CRP level of at least $10 \mathrm{mg} / \mathrm{L}, 37 \%$ of patients in the certolizumab groups had a response at week 6 as compared with $26 \%$ in placebo group $(p=0.04)$. In the overall population, response rates at week 6 were $35 \%$ in the certolizumab group and $27 \%$ in the placebo group $(\mathrm{p}=0.02)$. At weeks 6 and $26,23 \%$ of patients in the certolizumab groups had a response compared with $16 \%$ of patients in the placebo group $(p=0.02)$. Use of immunosuppressive agents, concomitant steroids, previous treatment with infliximab and smoking status were not associated with the magnitude of response. At week 26, 30\% of patients in the certolizumab group had fistula closure as compared with $31 \%$ in the placebo group.

Another important endpoint is to achieve and maintain long-term remission in Crohn's disease. Two studies have assessed the long-term efficacy of certolizumab for maintenance of response and remission, PRECISE $2^{45}$ and PRECISE $3 .{ }^{46}$ In PRECISE 2, there was an induction phase in which 668 patients received three subcutaneous injections doses of certolizumab $400 \mathrm{mg}$ at week 0,2 , and 4 . At week 6 , $64.1 \%$ patients $(428 / 668)$ had clinical response and were than randomized to the maintenance phase, receiving certolizumab $400 \mathrm{mg} / \mathrm{kg}$ or placebo every 4 weeks up to week 26 . At week 26, in the certolizumab group response rate was $63 \%$ compared with $36 \%$ in the placebo group $(\mathrm{p}<0.001)$; in addition, $48 \%$ of patients in the certolizumab group had 
remission at week 26 compared with $29 \%$ in the placebo group $(\mathrm{p}<0.001)$.

The study was centrally randomized and group assignment was stratified according to serum CRP level ( $\geq 10 \mathrm{mg} / \mathrm{L}$ or $<10 \mathrm{mg} / \mathrm{L}$ ), concurrent use of steroids, and immunosuppressive agents. In the intention to treat analysis, response rates at week 26 were greater among patients receiving maintenance therapy with certolizumab than among those receiving placebo, both for patients receiving concomitant immunosuppressive agents $(61 \%$ vs $33 \%)(p<0.001)$ and those without $(64 \%$ vs $39 \%)(p<0.001)$. No significant interactions between group assignment and smoking status or body mass index were found.

Among patients with a baseline CRP serum level of less than $10 \mathrm{mg} / \mathrm{L}$, response rates at week 26 were significantly greater in the certolizumab group (64\%) compared with placebo groups $(39 \%)(\mathrm{p}<0.001)$; similarly remission rate was $54 \%$ in the certolizumab group compared with $31 \%$ in the placebo group $(\mathrm{p}<0.001)$.

The PRECISE 3 was an open label extension study that recruited patients from PRECISE 1 and 2. Patients enrolled received certolizumab $400 \mathrm{mg}$ subcutaneously every 4 weeks. Two populations were analyzed: patients induced and treated for 24 weeks with certolizumab (PRECISE 1 and 2); patients who responded to induction therapy with certolizumab, but were than randomized to placebo in PRECISE 2.

At week 80 , more than $80 \%$ of patients achieved a clinically meaningful response and remission rate. Therefore, certolizumab $400 \mathrm{mg}$ administered every 4 weeks was an effective long-term maintenance therapy for patients who had responded to certolizumab induction therapy.

PRECISE 4 was an open label extension study that assessed the effectiveness of re-induction followed by maintenance therapy with certolizumab in patients who had experienced a significant clinical worsening of Crohn's disease ${ }^{47}$ Patients who withdrew after week 2 in PRECISE 1 or week 6 in PRECISE 2 with clinical worsening entered in PRECISE 4 and received re-induction with certolizumab $400 \mathrm{mg}$ subcutaneously at week 0, 2, 4 and then every 4 weeks. The rates of response at week 4 (45.7\%), 24 (57.1\%) and $52(69.3 \%)$ indicated that re-induction with a single dose of certolizumab followed by a standard 4-weekly stable dose could restore clinical response and remission.

Another important issue to evaluate is the efficacy of certolizumab in patients previously treated with infliximab.

About one third of patients with active Crohn's disease who had been treated with infliximab had no response to this drug after three induction doses. ${ }^{48}$ In addition, about one third of patients who might initially respond to infliximab therapy may subsequently lose the response or become intolerant over the first year of therapy. In PRECISE 2 a significant difference in the response rate at week 26 between the certolizumab group and the placebo group was found for patients who had previously received infliximab (44\% vs $25 \%$ ) (p < $<.001)$.

In WELCOME, a 26-week open label induction, double-blind maintenance trial, ${ }^{40,49} 539$ patients who had loss of response or intolerance to infliximab received certolizumab $400 \mathrm{mg}$ subcutaneously at weeks 0,2 , and 4 . At week 6, 62.2\% patients had clinical response and 39.3\% had remission.

These data were confirmed a study that reported the efficacy of certolizumab for induction of response and remission in a case series of 21 Crohn's disease patients who were refractory or had lost response to infliximab. ${ }^{50}$ At week 4, 52\% patients achieved clinical response and $42 \%$ were in remission. ${ }^{40,50}$ These findings are in contrast with CHARM, ${ }^{51}$ which reported efficacy of adalimumab as maintenance therapy for moderate to severe Crohn's disease. In this trial, patients who were naïve to antiTNF therapy had slightly better results at weeks 26 and 56 than patients who had previously received antiTNF therapy; however the difference did not reach statistical significance.

The concomitant use of immunomodulator with an antiTNF agent has been a topic of great interest and debate. Initially, it was assumed that the use of concomitant immunomodulators could improve the efficacy of antiTNF- $\alpha$ therapy (specifically infliximab), probably by decreasing immunogenicity. Subsequently, data emerged suggesting that the efficacy of TNF antagonists used as monotherapy was equivalent to combination therapy with TNF antagonists and immunomodulators. ${ }^{52}$ Preliminary data from the pivotal SONIC (Study of Biologic and Immunomodulator Naive Patients in Crohn's Disease) trial have been reported..$^{53}$ This study compared the efficacy outcomes in patients with Crohn's disease naïve to immunomodulators treated with azathioprine, infliximab, or a combination of azathioprine and infliximab. Patients eligible for the study had received previous treatment only with corticosteroids and/or 5-aminosalicylates. Due to the characteristics of the inclusion criteria, patients had a short duration of Crohn's disease, approximately 2 years before study entry. Week 26 steroid-free remission (CDAI < 150) was the primary endpoint, with week 54 endoscopic remission as a second important endpoint. At week 26, patients receiving azathioprine in combination with infliximab had the highest rate of remission $(57 \%)$ compared with infliximab alone 
(44\%) or azathioprine alone (30\%). Endoscopic remission rates paralleled clinical remission rates, and patients on combination therapy fared the best, while those receiving infliximab alone fared second best, and those on azathioprine alone fared the worst. Mucosal healing at week 26 was shown in $43.9 \%$ of the patients treated with infliximab + azathioprine, $30.1 \%$ of those treated with infliximab alone, and $16.5 \%$ of those treated with azathioprine alone.

\section{Certolizumab safety}

A recently study ${ }^{51}$ analyzed the safety data collected from patients who were enrolled in the different clinical trials using certolizumab. 1313 patients who had received continuous treatment with certolizumab $400 \mathrm{mg}$ were entered in the study. All patients received $\geq 4$ week of certolizumab and were stratified into 4 groups based on the duration of treatment $(>3$ months; $>6$ months; $>9$ months; $>12$ months). Rates of common adverse event were stable across exposure categories with the exception of infections, which increased with duration of exposure to certolizumab $(47.5 \%$ if $>4$ weeks vs $60 \%$ if $>6$ months).

In PRECISE 1 there were 4 cases of cancer ( 2 in the certolizumab group and 2 in the placebo group) and 7 cases of serious infections $(2 \%)$ in the certolizumab group and 3 cases in the placebo group (1\%).

In PRECISE 2 serious adverse events occurred in $6 \%$ of patients in the certolizumab group and $7 \%$ in the placebo group.

Although these results indicate that certolizumab does not increase the risk of serious adverse events, they should be interpreted with caution because the sample size was not large and the follow up might not have been long enough to pick up serious adverse events. Moreover, differences in the molecular structure compared with the other antiTNF agents may explain the different side-effects but data are lacking thus far.

Another issue is the potential development of anticertolizumab antibodies and their clinical implications. In Schreiber's study, ${ }^{45}$ anticertolizumab antibodies were found in the $12.3 \%$ of patients receiving certolizumab $400 \mathrm{mg}$ while in PRECISE I anticertolizumab antibodies were found in the $8 \%$ of patients and $4 \%$ of those receiving concomitant immunosuppressive therapy. ${ }^{44}$ The plasma concentration of certolizumab appeared to be lower in the presence of antibodies, but no decrease in efficacy was reported.

\section{Comparative efficacy of infliximab, adalimumab and certolizumab}

Three antiTNF agents have been approved by the FDA for treatment of Crohn's disease (Table 3). However it is difficult to directly compare the efficacy of certolizumab with infliximab and adalimumab in the absence of head-to-head studies. Nevertheless, the results of maintenance trials of these three drugs are similar; basically patients who had a clinical response at an early time point were randomized to receive either placebo or antiTNF agents and the rates of remission were taken at weeks 26 and 30.

In ACCENT1, 52 the maintenance trial with infliximab, $58 \%$ of patients responded to open label therapy at week 2 and $30 ; 39 \%$ of patients were in remission on infliximab $5 \mathrm{mg} / \mathrm{kg}$ compared with $21 \%$ patients receiving placebo.

In CHARM, ${ }^{53}$ the maintenance trial with adalimumab, $58 \%$ patients responded to open label therapy at week 4 and 26 compared with $40 \%$ patients receiving placebo.

In PRECISE 2 study, ${ }^{45} 64 \%$ patients responded to certolizumab $400 \mathrm{mg}$; 48\% were in remission compared $29 \%$ patients in the placebo group.

Therefore the efficacy of these three agents for induction and remission was roughly similar. At the moment selection of antiTNF agents for induction or salvage therapy is based on local availability and regulatory restriction. However, while adalinumab and certolizumab have proven effective in patients with loss of response to infliximab, no controlled data on infliximab as salvage therapy are available.

\section{Effect of certolizumab on quality of life}

Patients with Crohn's disease have poor health-related quality of life (HRQL). This is usually estimated with the inflammatory bowel disease questionnaire (IBDQ) which assesses 4 aspects of a patient's life: $:^{54}$

Table 3 Principal characteristics of infliximab, abalimumab and certolizumab

\begin{tabular}{llll}
\hline & Infliximab & Adalimumab & Certolizumab \\
\hline Biological characteristics & Recombinant chimeric mouse-human & Recombinant fully human monoclonal & Fc-free pegylated antiTNF- $\alpha$ \\
& nonoclonal antiTNF- $\alpha$ antibody & antiTNF- $\alpha$ antibody & No \\
Apoptotic effects & Yes & Yes & Subcutaneous \\
Administration route & Intravenous & Subcutaneous & \\
\hline
\end{tabular}


1) symptoms directly related to primary bowel symptoms;

2) systemic symptoms;

3) emotional function;

4) social function.

The IBDQ scores range from 32 to 224 , higher scores indicating better quality of life. An increase of at least 16 points in the total score is regarded as clinically meaningful. ${ }^{55}$

In Schreiber's phase II study, for all treatment groups, there was an increase in IBDQ total scores within 2 weeks of treatment that paralleled the change in CDAI scores. The large change from baseline at week 2 was observed in the certolizumab $400 \mathrm{mg}$ group (22.8 points compared with 10.6 points in the placebo group) $(\mathrm{p}=0.002)$. At week 12 , the IBDQ total scores were $156.5 \pm 37.36$ in the certolizumab group compared with $140.5 \pm 35.88$ in the placebo group. ${ }^{42}$

In PRECISE 2, 60\% patients in the certolizumab group had a IBDQ response at week 26 compared with $43 \%$ in the placebo group ( $\mathrm{p}<0,001)$.

These data suggest that certolizumab $400 \mathrm{mg}$ might significantly improve the quality of life in patients with moderate to severe Crohn' disease.

\section{Conclusion}

AntiTNF agents have an important role in the treatment of Crohn's disease refractory to conventional therapy. Compared with adalinumab and infliximab, certolizumab pegol is similarly effective for a rapid induction of response (about $50 \%$ of patients) and long-term maintenance of clinical response or remission.

Moreover, certolizumab significantly improves quality of life in patients with active Crohn's disease.

Certolizumab appears to be safe since no clinical trials have reported an increased risk of serious adverse events; however, more data from longer duration studies and larger numbers of patients are still needed.

Of note, certolizumab might be an additional treatment option in patients who have lost response to or were intolerant to other antiTNF agents.

\section{Disclosures}

The authors have conflicts of interest to disclose.

\section{References}

1. Stange EF, Travis SP, Vermiere S, et al. European evidence based consensus on the diagnosis and management of Crohn's disease: definitions and diagnosis. Gut. 2006:55(Suppl 1):i1-15.

2. Schwartz DA, Loftus Jr EV, Tremaine WJ, et al. The natural history of fistulzing Crohn's disease in Olmsted Country. Minnesota. Gastroenterology. 2002;122(4):875-880.
3. Loftus EV. Clinical epidemiology of inflammatory bowel disease: incidence, prevalence and environmental influences. Gastroenterology. 2004;126(6):1504-1517.

4. Loftus Jr EV, Schoenfeld P, Sandborn WJ. The epidemiology and natural history of Crohn's disease in population-based patient cohorts from North America: a systematic review. Aliment Pharmacol Ther. 2002;16(1):51-60

5. Loftus Jr EV, Sandborn WJ. Epidemiology of inflammatory bowel disease. Gastroenterol Clin North Am. 2002;31(1):1-20.

6. Xavier RJ, Podolsky DK. Unrevealing the pathogenesis of inflammatory bowel disease. Nature. 2007;448:427-434.

7. Russell RK, Satsangi J. IBD: a family affair. Best Pract Res Clin Gastroenterol. 2004;18:525-539.

8. Hugot JP, Chamaillard M, Zouali H, et al. Association of NOD2 leucine-rich repeat variants with susceptibility to Crohn's disease. Nature. 2001;411:599-603.

9. Cho JH, Weaver CT. The genetics of inflammatory bowel disease. Gastroenterology. 2007;133:1327-1339.

10. Rosenstiel P, Huse K, Till A, et al. A short isoform of NOD2/CARD15, NOD2-s, is an endogenous inhibitor of NOD2 receptor-interacting protein kinas 2-induced signalling pathways. Proc Natl Acad Sci U S A. 2006;103::3280-3285.

11. Rioux JD, Daly MJ, Silverberg MS, et al. Genetic variation in the 5q31 cytokine gene cluster confers susceptibility to Crohn's disease. Nat Genet. 2001;29(2):223-228.

12. Duerr RH, Taylor KD, Brant SR, et al. A genome-wide association study identifies IL23R as an inflammatory bowel disease gene. Science. 2006;314:1461-1463.

13. Peltekova VD, Wintle RF, Rubin LA, et al. Functional variation of OCTN cation transporter genes are associated with Crohn's disease. Nat Genet. 2004;36:471-475.

14. Economou M, Trikalinos TA, Loizou KT, et al. Differential effects of NOD2 variants on Crohn's disease risk and phenotype in diverse populations: a metaanalysis. Am J Gastroenterol. 2004;99: 2393-2404.

15. Brant SR, Picco MF, Achkar JP, et al. Defining complex contributions of NOD2CARD15 gene mutations, age, at onset, and tobacco use on Crohn's disease phenotypes. Inflamm Bowel Dis. 2003;9:281-289.

16. Alvarez-Lobos M, Arostegui JI, Sans M, et al. Crohn's disease patients carrying Nod2/CARD15 gene variants have an increate and early need for first surgery due to structuring disease and higher rate of surgical recurrence. Ann Surg. 2005;242:693-700.

17. Mathew CG. New links to the pathogenesis of Crohn's disease provided by genome-wide association scans. Nat Rev Genet. 2008;9:9-14.

18. Barrett JC, Hansoul S, Nicolae DL, et al. Genome-wide association defines more than 30 distinct susceptibility loci for Crohn's disease. Nat Genet. 2008;40:955-962.

19. Armotage EL, Aldhours MC, Anderson N, et al. Incidence of juvenileonset Crohn's disease in Scotland: association with northern latitude and affluence. Gastroenterology. 2004:127(4):1051-1057.

20. Cosnes J, Beagugerie L, Carbonnel F, et al. Smoking cessation and the course of Crohn's disease: an intervention study. Gastroenterology. 2001;120 (5):1093-1099.

21. Sanchez-Muñoz F, Dominguez-Lopez A, Yamamoto-Furusho JK. Role of cytokines in inflammatory bowel disease. World Gastroenterol. 2008; 14 (27); 4280-4288

22. Arseneau KO, Tamagawa H, Pizarro TT, et al. Innate and adaptive immune responses related to IBD pathogenesis. Curr Gastroenterol Rep. 2007;9 (6):508-512.

23. Cominelli F. Cytokine based therapies for Crohn's disease. New paradigms. N Engl J Med. 2004;351:2045-2048.

24. Su C, Linchestein GR, Krok K, et al. A meta-analysis of the placebo rates of remission and response in clinical trials of active Crohn's disease. Gastroenterology. 2004;126:1257-1269.

25. Travis SP, Stange EF, Lèmann M, et al. European evidence based consensus on the diagnosis and management of Crohn's disease: current management. Gut. 2006;55(Suppl I):i16-i35. 
26. Reinecker HC, Steffen M, Witthoeft T, et al. Enhanced secretion of tumor necrosis factor alfa, IL6, and IL1-beta by isolated lamina propria mononuclear cells from patients with ulcerative and Crohn's colitis. Clin Exp Immunol. 1993;94:174-181.

27. Murch SH, Lamkin VA, Savage MO, et al. Serum concentrations of tumor necrosis factor alpha in childhood chronic inflammatory bowel disease. Gut. 1991;32:913-917.

28. Braegger CP, Nicholls S, Murch SH, et al. Tumor necrosis alpha in stool as marker of intestinal inflammation. Lancet. 1992;339:89-91.

29. Beart F, Noman M, Vermiere S, et al. Influence of immunogenicity on long-term efficacy of infliximab in Crohn's disease. N Engl J Med. 2003;348:601-608.

30. Lang L. FDA approves Cimzia to treat Crohn's disease. Gastroenterology. 2008;134:1819.

31. Lugering A, Schmidt $\mathrm{M}$, Lugering $\mathrm{N}$, et al. Infliximab induces apoptosis in monocytes from patients with chronic active Crohn's disease by using a caspase-dependent pathway. Gastroenterology. 2001;121:1145-1157.

32. Shen C, Assche GV, Colpaert S, et al. Adalimumab induces apoptosis of human monocytes: a comparative study with infliximab and etanercept. Aliment Pharmacol Ther. 2005;21:251-258.

33. Van den Brande JM, Braat H, van den Brink GR. Infliximab but not etanercept induced apoptosis in lamina propria T-lymphocytes from patients with Crohn's disease. Gastroenterology. 203;124:1774-1785.

34. Ten Hove T, van Montfrans C, Peppelenbosch MP, et al. infliximab treatment induces apoptosis of lamina propria T-lymphocyte in Crohn's disease. Gut. 2002;50:206-211.

35. Scallon BJ, Moore MA, Trinh $\mathrm{H}$, et al. Chimeric anti-TNF $\alpha$ monoclonal antibody cA2 binds recombinant trans membrane TNF $\alpha$ and activate immune effector functions. Cytokine. 1995;7:251-259.

36. Kirchner S, Holler E, Haffner S, et al. Effect of different tumor necrosis factor (TNF) reactive agents on reverse signaling of membrane integrated TNF in monocytes. Cytokine. 2004;28:67-74.

37. Nesbitt A, Fossati G, Bergin M, et al. Mechanism of action of certolizumab pegol (CDP870): in vitro comparison with other anti-tumor necrosis factor $\alpha$ agents. Inflamm Bowel Dis. 2007;13:1323-1332.

38. Fossati G, Nesbitt AM. In vitro complement-dependent cytotoxicity and antibody-dependent cellular cytotoxicity by the anti-TNF agents adalimumab, etanercept, infliximab, and certolizumab pegol (CDP870). Am J Gastroenterol. 2005;100(Suppl 9):S299.

39. Nesbitt AM, Henry AJ. High affinity and potency of the pegylated fab' fragment CDP870. Direct comparison with other anti-TNF agents. Am J Gastroenterol. 2004;99(Suppl 10):S253.

40. Shao LM, ChenMY Chen QY, et al. Systematic review: the efficacy and safety of certolizumab pegol in Crohn's disease. Aliment Pharmacol Ther. 2009;29:605-614.

41. Winter TA, Wright J, Ghosh S, et al. Intravenous CDP870, a PEGylated Fa' fragment of humanized antitumor necrosis factor antibody, in patients with moderate to severe Crohn's disease: an exploratory study. Aliment Pharmacol Ther. 2004;20:1337-1346.

42. Schreiber S, Rutgeerts P, Fedorak R, et al. A randomized, placebocontrolled trial of certolizumab pegol (CDP870) for treatment of Crohn's disease. Gastroenterology. 2005;129:807-818.
43. Fagan EA, Dyck RF, Maton PN, et al. Serum levels of C-reactive protein in Crohn's disease and ulcerative colitis. Eur J Clin Invest. 1982;12:351-359.

44. Sandborn WJ, Fegan BG, Stoinov S, et al. Certolizumab pegol for the treatment of Crohn's disease. N Engl J Med. 2007;357:228-238.

45. Schreiber S, Khaliqkareemi M, Lawrance IC, et al. Maintenance therapy with certolizumab pegol for Crohn's disease. $N$ Engl J Med. 2007:357:239-250.

46. Schreiber S, Hanauer SB, Feagan G, et al. Long-term treatment with certolizumab pegol for up to 18 month in patients with active Crohn's disease: PRECISE 3efficacy results. Gastroenterology. 2007;132:A504.

47. Sandborn WJ, Hanauer SB, Rutgeerts PJ, et al. Re-induction and maintenance therapy with subcutaneous certolizumab pegol in patients with Crohn's disease following treatment failure: PRECISE4 results. Gastroenterology. 2007;132:A505.

48. Rutgeerts P, Feagan BG, Lichenstein GR, et al. Comparison of scheduled and episodic treatment strategies of infliximab in Crohn's disease. Gastroenterology. 2004;126:402-413.

49. Vermiere S, Abrreu MY, D'Haens G, et al. Efficacy and safety of certolizumab pegol in patients with active Crohn's disease who previously lost response ore were intolerant to infliximab: open label induction preliminary results of the WELCOME study. Gastroenterology. 2008;134:A67.

50. Danese S, Mocciaro F, Guidi L, et al. Successful induction of clinical response and remission with certolizumab pegol in Crohn's disease refractory or intolerant to infliximab: a real-life multicenter experience of compassionate use. Inflamm Bowel Dis. 2008;14:1168-1170.

51. Colombel JF, Sandborn WJ, Rutgeerts P, et al. Adalimumab for maintenance of clinical response and remission in patients with Crohn's disease: CHARM trial. Gastroenterology. 2007;132:52-65.

52. Tracey D, Klareskorg L, Sasso EH, et al. Tumor necrosis factor antagonist mechanisms of action: a comprensive review. Pharmacol Ther. 2008;117:244-279.

52. D'Haens G, Baert F, van Assche G, et al. Early combined immunosuppression or conventional management in patients with newly diagnosed Crohn's disease: an open randomised trial. Lancet. 2008;371:660-667.

53. Sandborn W, Rutgeerts P, Reinishch W, et al. SONIC: a randomized, double blind, controlled trial comparing infliximab and infliximab plus azathioprine to azathioprine in patients with Crohn's disease naïve to immunomodulators and biologic therapy. Am J Gastroenterol. 2008;103:1117.

54. Lichtenstein GR, Colombel JF, Bloomfield R, et al. Long-term safety of an anti-TNF drug by duration of exposure compared to non anti-TNF exposed patiens with Crohn's disease: novel data from the certolizumab pegol development program. Gastroenterology. 2008;134:(3)A68.

55. Hanauer SB, Feagan BG, Lichtenstein GR, et al. Maintenance infliximab for Crohn's disease: the ACCENT I randomized trial. Lancet. 2002;359:1541-1549.

56. Guyatt GH, Mitchell A, Irvine EJ, et al. A new measure of health status for clinical trials in inflammatory bowel disease. Gastroenterology. 1989;96:804-810.

57. Irvine EJ, Feagan B, Rochon J, et al. Quality of life: a valid and reliable measure of therapeutic efficacy in the treatment of inflammatory bowel disease. Gastroenterology. 1994;106:287-296.
Clinical and Experimental Gastroenterology

\section{Publish your work in this journal}

Clinical and Experimental Gastroenterology is an international, peerreviewed, open access journal, publishing all aspects of gastroenterology in the clinic and laboratory, including: Pathology, pathophysiology of gastrointestinal disease; Investigation and treatment of gastointestinal disease; Pharmacology of drugs used in the alimentary tract;
Dovepress

Immunology/genetics/genomics related to gastrointestinal disease This journal is indexed on CAS. The manuscript management system is completely online and includes a very quick and fair peer-review system. Visit http://www.dovepress.com/testimonials.php to read real quotes from published authors. 